\title{
Effects of oocyte maturation media on development of pig embryos produced by in vitro fertilization
}

\author{
W. H. Wang, L. R. Abeydeera, T. C. Cantley and B. N. Day* \\ Department of Animal Sciences, University of Missouri-Columbia, Columbia, MO 65211, USA
}

\begin{abstract}
Few embryos derived from pig oocytes matured and inseminated in vitro are able to develop to blastocysts in culture. The present study was conducted to examine the effects of oocyte maturation media on the developmental ability of pig oocytes matured and inseminated in vitro. Follicular oocytes collected from ovaries of prepubertal gilts were cultured in NCSU23 medium, tissue culture medium 199 or a modified Whitten's medium. All of the media were supplemented with $0.57 \mathrm{mmol}$ cysteine $\mathrm{I}^{-1}$ and $10 \%$ pig follicular fluid. After maturation, some of the oocytes were used for examination of intracellular glutathione content, nuclear maturation and cortical granule distribution. The other oocytes were inseminated in vitro in a modified Tris-buffered medium with cryopreserved, ejaculated spermatozoa for examination of cortical reaction, sperm penetration, male pronuclear formation and blastocyst development. No differences $(P>0.05)$ were observed in nuclear maturation, cortical granule distribution, sperm penetration, male pronuclear formation, polyspermy and cleavage in oocytes matured in the three media. However, significant $(P<0.05)$ differences were observed in glutathione content, cortical granule exocytosis, blastocyst development and number of cells in blastocysts. NCSU23 medium gave the best results of the three media, resulting in $5.8 \mathrm{pmol}$ glutathione per oocyte, $97 \%$ of cortical granule exocytosis, $30 \%$ blastocyst development and $36.8 \pm 17.0$ cells per blastocyst. These results clearly indicate that cytoplasmic maturation of pig oocytes was significantly affected by oocyte maturation media even in the presence of cysteine and pig follicular fluid. In addition, it was demonstrated that a large proportion of pig oocytes can develop to blastocysts under in vitro conditions.
\end{abstract}

\section{Introduction}

Pig oocytes matured and inseminated in vitro can develop to blastocysts after transfer of fertilized oocytes to the oviduct (Mattioli et al., 1989; Yoshida et al., 1990; Funahashi et al., 1994a). Only recently have some of the embryos that resulted from in vitro maturation (IVM) and in vitro fertilization (IVF) developed to blastocysts under in vitro conditions (Nagashima et al., 1993; Funahashi et al., 1994b, 1996; Rath et al., 1996). However the developmental rates are very low when compared with those of oocytes matured and fertilized in vivo (Beckmann and Day, 1993; Nagashima et al., 1993; Petters and Wells, 1993; Rath et al., 1996; Dobrinsky et al., 1996). This low developmental ability was thought to be the result of incomplete cytoplasmic maturation of pig oocytes matured in vitro and high polyspermic penetration of oocytes inseminated in vitro (Niwa, 1993). However, considerable improvement has been made in the IVM and IVF of pig oocytes (Niwa, 1993; Nagai, 1996). Low male pronuclear (MPN) formation has almost been overcome by the removal of fetal calf serum from the oocyte maturation medium (Naito et al., 1988; Funahashi and Day, 1993a), supplementation of pig follicular fluid (pFF)

*Correspondence.

Received 5 March 1997.
(Naito et al., 1988) and cysteine (Yoshida et al., 1993a) to the maturation medium, and the adjustment of hormones (Funahashi and Day, 1993b) during the maturation of oocytes. However, different media have been used in different laboratories. Tissue culture medium (TCM)-199, a common medium for oocyte maturation, has been used in most of the laboratories (Mattioli et al., 1989; Yoshida et al., 1990; Wang et al., 1991; Funahashi et al., 1994a, b). Blastocyst development (Mattioli et al., 1989; Yoshida et al., 1990; Nagashima et al., 1993; Funahashi et al., 1994a, b) and birth of piglets (Mattioli et al., 1989) resulting from oocytes matured in TCM-199 have been reported, although the efficiency is low. A modified Whitten's medium (mWM) (Funahashi et al., 1994c) and a bovine serum albumin (BAS)-free NCSU23 medium (Funahashi et al., 1996), which were primarily developed for the culture of mouse (Whitten and Biggers, 1968) and pig (Petters and Wells, 1993) preimplantation embryos, have been shown to support pig oocyte maturation in vitro. Funahashi et al. (1994b, 1996) compared TCM-199 with mWM, and mWM with NCSU23 medium during oocyte maturation and found that cytoplasmic maturation of pig oocytes is significantly affected by the maturation medium. Some modifications to the composition of medium, such as a reduction in the concentration of $\mathrm{NaCl}$ (Funahashi et al., 1994c) and the addition of organic osmolytes 
Table 1. Composition of media used for in vitro maturation (IVM), in vitro fertilization (IVF) and in vitro culture (IVC)

\begin{tabular}{|c|c|c|c|c|c|}
\hline \multirow{2}{*}{$\begin{array}{l}\text { Concentration } \\
\left(\mathrm{mmol} \mathrm{I}^{-1}\right)\end{array}$} & \multicolumn{3}{|c|}{ IVM medium } & \multirow{2}{*}{$\begin{array}{l}\text { IVF } \\
\text { medium } \\
\text { mIBM }\end{array}$} & \multirow{2}{*}{$\begin{array}{c}\text { IVC } \\
\text { medium } \\
\text { NCSU23 }\end{array}$} \\
\hline & TCM-199 & NCSU23 & $\mathrm{mWM}$ & & \\
\hline $\mathrm{NaCl}$ & 116.36 & 108.73 & 68.49 & 113.1 & 108.73 \\
\hline $\mathrm{KCl}$ & 5.36 & 4.78 & 4.78 & 3.0 & 4.78 \\
\hline $\mathrm{CaCl}_{2}$ & 1.80 & 1.70 & - & 7.5 & 1.70 \\
\hline $\mathrm{KH}_{2} \mathrm{PO}_{4}$ & - & 1.19 & 1.19 & - & 1.19 \\
\hline $\mathrm{MgSO}_{4} \cdot 7 \mathrm{H}_{2} \mathrm{O}$ & 0.81 & 1.19 & 1.19 & - & 1.19 \\
\hline $\mathrm{NaHCO}_{3}$ & 26.19 & 25.07 & 25.07 & - & 25.07 \\
\hline Glucose & 5.55 & 5.55 & 5.56 & 11.0 & 5.55 \\
\hline Sodium lactate & - & 一 & 25.20 & - & - \\
\hline Sodium pyruvate & - & - & 0.33 & 5.0 & - \\
\hline Calcium lactate & 一 & - & 1.71 & 一 & 一 \\
\hline Glutamine & 0.68 & 1.0 & - & - & 1.0 \\
\hline Taurine & - & 7.0 & - & - & 7.0 \\
\hline Hypotaurine & - & 5.0 & - & - & 5.0 \\
\hline Tris & - & - & - & 20.0 & - \\
\hline Penicillin $\mathrm{G}$ (i.u. $\mathrm{ml}^{-1}$ ) & 100 & 100 & 100 & 100 & 100 \\
\hline Streptomycin $\left(\mu \mathrm{g} \mathrm{ml}^{-1}\right)$ & 50 & 50 & 50 & 50 & 50 \\
\hline $\mathrm{pFF}(\%, \mathrm{v} / \mathrm{v})$ & 10 & 10 & 10 & - & - \\
\hline $\mathrm{BSA}\left(\mathrm{mg} \mathrm{ml}^{-1}\right)$ & - & - & - & $2^{b}$ & $4^{c}$ \\
\hline Cysteine & 0.57 & 0.57 & 0.57 & 0.57 & - \\
\hline Caffeine & 一 & - & 一 & - & - \\
\hline
\end{tabular}

a Partial listing of components of TCM199 purchased from Gibco, Cat. No. 31100-035.

${ }^{b}$ Fraction V, Sigma, Cat. No. A-7888.

'Fraction V, Sigma, Cat. No. A-8022.

mWM, modified Whitten's medium; mTBM, modified Tris buffer medium; pFF, porcine follicular fluid.

(Funahashi et al., 1996), significantly improve oocyte cytoplasmic maturation. However, the blastocyst developmental rate is still low $(<10 \%)$.

Supplementation of maturation medium with cysteine enhances the amount of glutathione in pig oocytes and improves MPN formation after sperm penetration (Yoshida et al., 1993a). Greater amounts of glutathione improve the developmental ability of preimplantation embryos in cattle (Takahashi et al., 1993; Lim et al., 1996). It is likely that a supplement of cysteine during oocyte maturation not only increases MPN formation but also improves embryo development.

One of the reasons that developmental competence of pig oocytes has not been widely studied is that high proportions of IVM/IVF oocytes are polyspermic. Polyspermy results in early embryo death, which limits the study on preimplantation embryo development under in vitro conditions. A modified Tris buffer medium (mTBM) has been found to not only support sperm penetration but also to reduce polyspermic penetration of pig oocytes in vitro when frozen-thawed semen is used (Abeydeera and Day, in press). It would appear that mTBM can also support oocytes to undergo normal cortical reaction during IVF.

Putting the recent progress in IVM and IVF of pig oocytes together, it is possible to develop a system for the production of pig embryos under in vitro conditions. In the present study, using BSA-free NCSU23 medium, TCM-199 and mWM, supplemented with cysteine and pFF, as the oocyte maturation media and mTBM as the IVF medium, the in vitro developmental ability of pig embryos that resulted from IVM/IVF oocytes was examined, with special reference to the effects of maturation media on developmental competence.

\section{Materials and Methods}

\section{Media}

Three maturation media were used in this study: TCM-199 (with Earle's salts, Gibco, Grand Island, NY), BSA-free NCSU23 medium (Petters and Wells, 1993) and mWM (Funahashi et al., 1994c). All media were supplemented with $0.57 \mathrm{mmol}$ cysteine $\mathrm{I}^{-1}$ (Sigma Chemical Co., St Louis, MO) and $10 \%(\mathrm{v} / \mathrm{v}) \mathrm{pFF}$. The pFF was collected from follicles (3-5 $\mathrm{mm}$ diameter) of prepuberal pig ovaries. After centrifugation at $1500 \mathrm{~g}$ for $30 \mathrm{~min}$ at $4^{\circ} \mathrm{C}$, the suspension was filtered through $1.2 \mu \mathrm{m}$ syringe filters and stored at $-20^{\circ} \mathrm{C}$ until use. The same central pool of pFF was used for all three maturation media. The media used for IVF was a Tris buffer medium (Berger and Horton, 1988) modified by this laboratory (Abeydeera and Day, in press). Embryo culture medium was NCSU23 medium supplemented with $4 \mathrm{mg}$ BSA (Fraction $\mathrm{V}, \mathrm{A}-8022) \mathrm{ml}^{-1}$ (Petters and Wells, 1993). The detailed compositions of these media are shown (Table 1). 


\section{Collection and culture of oocytes}

The collection and culture of oocytes were based on procedures reported by Funahashi et al. (1996). Briefly, ovaries collected from prepuberal gilts at a local abattoir were put in $0.9 \%(\mathrm{w} / \mathrm{v}) \mathrm{NaCl}$ at $25^{\circ} \mathrm{C}$ and maintained at this temperature while being transported to the laboratory. Three to four hours after exsanguination, follicular oocytes were aspirated from antral follicles (3-5 $\mathrm{mm}$ diameter) using an 18 gauge needle fixed to a $10 \mathrm{ml}$ disposable syringe. After washing four times with Hepes-buffered Tyrodes medium containing $0.1 \%(w / v)$ polyvinyl alcohol, oocytes were washed three times with a specified maturation medium and each group of 50 oocytes surrounded by compact cumulus were transferred to a $500 \mu \mathrm{l}$ drop of the same medium which had been previously covered with warm paraffin oil (Fisher Scientific, Pittsburgh, PA) in a polystyrene culture dish (Falcon 1008, Beckton Dickinson Labware, Lincoln Park, NJ) and equilibrated in an atmosphere of $5 \% \mathrm{CO}_{2}$ in air overnight. Five microlitres of water containing 1000 i.u. equine chorionic gonadotrophin $(\mathrm{eCG}) \mathrm{ml}^{-1}$ (Intervet America Inc., DE) and 1000 i.u. hCG $\mathrm{ml}^{-1}$ (LyphoMed Inc., Rosemont, IL) were added to the culture drops containing oocytes, resulting in a final concentration of 10 i.u. hormones $\mathrm{ml}^{-1}$. After culture for $22 \mathrm{~h}$, oocytes were washed three times and then cultured in maturation medium without hormones for another $22 \mathrm{~h}$ at $39^{\circ} \mathrm{C}, 5 \% \mathrm{CO}_{2}$ in air (Funahashi and Day, 1993b).

\section{In vitro fertilization of oocytes}

After culture, all oocytes were freed from cumulus and corona cells by treatment with maturation media containing $0.1 \%(w / v)$ hyaluronidase, obtained from bovine testis (Type I-S, H-3506; Sigma), and then washed three times with the insemination medium (mTBM). Thereafter, each 30 oocytes were transferred into a $50 \mu \mathrm{l}$ droplet of $\mathrm{mTBM}$ covered with paraffin oil. The dishes were kept in a $\mathrm{CO}_{2}$ incubator until spermatozoa were added for insemination. For IVF, one $0.2 \mathrm{ml}$ frozen semen pellet, made as described by Wang et al. (1991), was thawed at $39^{\circ} \mathrm{C}$ in $10 \mathrm{ml}$ PBS containing $1 \mathrm{mg} \mathrm{BSA} \mathrm{ml}{ }^{-1}$ (Fraction V, A-8022; Sigma) and antibiotics. After being washed three times, spermatozoa were resuspended with mTBM containing $2 \mathrm{mmol}$ caffeine $1^{-1}$ (Sigma), to give a concentration of to $1 \times 10^{6} \mathrm{cells} \mathrm{ml}^{-1}$, and $50 \mu \mathrm{l}$ of the sample was added to $50 \mu \mathrm{l}$ of the fertilization drops containing the oocytes. Six hours after insemination at $39^{\circ} \mathrm{C}$ in an atmosphere of $5 \% \mathrm{CO}_{2}$ in air, oocytes were removed from fertilization drops, washed four times and cultured in $500 \mu \mathrm{l}$ of culture medium in a four-well culture plate (Nunc, Roskilde) until examination.

\section{Assessment of cortical granules}

The methods for assessment of cortical granules were based on those described by Yoshida et al. (1993b) with a few modifications. Zonae pellucidae of oocytes were removed by putting the oocytes in PBS containing $0.1 \%(\mathrm{w} / \mathrm{v})$ pronase (Type XIV, P-8811; Sigma). After washing three times, oocytes were fixed with $3.7 \%(\mathrm{w} / \mathrm{v})$ paraformaldehyde (Sigma) in PBS for at least $30 \mathrm{~min}$ at room temperature, and then washed three times in PBS containing $3 \mathrm{mg} \mathrm{BSA} \mathrm{m} \mathrm{m}^{-1}$ and $100 \mathrm{mmol}$ glycine $1^{-1}$ (Sigma) for $5 \mathrm{~min}$ each time. After treating for $5 \mathrm{~min}$ in PBS containing $0.1 \%(\mathrm{v} / \mathrm{v})$ Triton X-100 (Sigma), oocytes were washed two additional times for $5 \mathrm{~min}$. Oocytes were then cultured in $100 \mu \mathrm{g}$ fluorescein isothiocyanate labelled peanut agglutinin $\mathrm{ml}^{-1}$ (Sigma) in PBS for $30 \mathrm{~min}$ in a dark box. After staining, the oocytes were washed three times in PBS containing $3 \mathrm{mg} \mathrm{BSA} \mathrm{ml}{ }^{-1}$ and $0.01 \%(\mathrm{v} / \mathrm{v})$ Triton $\mathrm{X}$-100. The nuclear status of oocytes was determined after staining with $10 \mu \mathrm{g}$ propidium iodide $\mathrm{ml}^{-1}$ (Sigma) in PBS for $1 \mathrm{~h}$ at $39^{\circ} \mathrm{C}$. These oocytes were then mounted on slides and observed by laser confocal microscopy.

Confocal microscopy was performed using a BioRad MRC600 equipped with a Krypton-argon ion laser, and mounted on an Optiphoto II Nikon microscope equipped with $\times 40$ and $\times 60$ objectives. Two sections in each oocyte were observed at magnifications of $\times 400$ or $\times 600$. The largest optical section is referred to as the equator of oocyte and the top surface section is referred to as the cortex of oocyte. In each section, the image was obtained by repeated laser scanning (eight times during $8 \mathrm{~s}$ ) to improve the signal: noise ratio. The numbers of cortical granules in the cortex were counted in squares of $100-1000 \mu \mathrm{m}^{2}$, and then the average number per $100 \mu \mathrm{m}^{2}$ of cortex in each oocyte was calculated. After evaluation of the number of cortical granules, oocytes were examined for nuclear stage and sperm penetration.

\section{Assay of glutathione}

The assay of glutathione was based on the procedures reported by Funahashi et al. (1996). Briefly, after culture, cumulus cells were removed completely from oocytes and oocytes were washed three times with a stock buffer $(0.2 \mathrm{~mol}$ sodium phosphate $~^{-1}$ containing $10 \mathrm{mmol}$ sodium EDTA $\mathrm{l}^{-1}$, $\mathrm{pH}$ 7.2). Five microlitres of stock buffer containing 10-30 oocytes was transferred to a $1.5 \mathrm{ml}$ microfuge tube. The oocytes were ruptured by agitation with a narrow-bore glass pipette, and $5 \mu$ l of $1.25 \mathrm{mmol}$ phosphoric acid $\mathrm{l}^{-1}$ (Sigma) was added to the tube. The tubes containing samples were kept in a freezer at $-30^{\circ} \mathrm{C}$ until assay. The concentration of glutathione in oocytes was determined by the 5,5'dithiobis-( 2 nitrobenzoic acid) and glutathione disulfide reductase recycling assay (Anderson, 1985).

Assessment of nuclear maturation, sperm penetration, pronuclear formation and number of cells in blastocyst

Matured, inseminated oocytes or day 7 blastocysts were mounted on slides, fixed in $25 \%(\mathrm{v} / \mathrm{v})$ acetic alcohol, stained with $1 \%(\mathrm{w} / \mathrm{v})$ orcein in $45 \%(\mathrm{v} / \mathrm{v})$ acetic acid, and examined under a phase-contrast microscope. Oocytes containing one polar body and a metaphase plate were regarded as matured. Oocytes were considered as penetrated when they had at least one swollen sperm head or a male pronucleus with the second polar body released and the corresponding sperm tail in the vitellus. Because oocytes were examined $12 \mathrm{~h}$ after insemination, sperm heads were found to be present as either swollen heads or male pronuclei. Only oocytes that contained a male pronucleus(ei) with an intact nuclear membrane were classified 
Table 2. Effects of different maturation medium on nuclear maturation and fertilization of pig oocytes in vitro ${ }^{a}$

\begin{tabular}{|c|c|c|c|c|c|c|c|}
\hline \multirow[b]{2}{*}{ Medium } & \multirow[b]{2}{*}{$\begin{array}{c}\text { Number of } \\
\text { oocytes } \\
\text { examined }\end{array}$} & \multirow{2}{*}{$\begin{array}{c}\text { Number of } \\
\text { oocytes } \\
\text { matured } \\
(\%)\end{array}$} & \multirow[b]{2}{*}{$\begin{array}{l}\text { Number of } \\
\text { oocytes } \\
\text { inseminated }\end{array}$} & \multicolumn{2}{|c|}{$\begin{array}{c}\text { Number of oocytes } \\
\text { penetrated }\end{array}$} & \multirow{2}{*}{$\begin{array}{c}\text { Number of } \\
\text { polyspermic } \\
\text { oocytes } \\
(\%)^{\mathrm{c}}\end{array}$} & \multirow{2}{*}{$\begin{array}{c}\text { Mean number } \\
\text { of spermatozoa } \\
\text { in penetrated } \\
\text { oocytes }\end{array}$} \\
\hline & & & & $\begin{array}{l}\text { Total } \\
(\%)^{b}\end{array}$ & $\begin{array}{c}\text { With male } \\
\text { pronucleus } \\
(\%)^{b}\end{array}$ & & \\
\hline $\mathrm{mWM}$ & 94 & $84(89)$ & 85 & $63(74)$ & $54(86)$ & $19(30)$ & 1.33 \\
\hline
\end{tabular}

aocytes used for examination of nuclear maturation ( $44 \mathrm{~h}$ after culture) and for insemination ( $12 \mathrm{~h}$ after insemination) were different subgroups. Experiments were repeated seven times.

'Percentage of the number of oocytes inseminated.

cPercentage of the total number of oocytes penetrated.

mWM, modified Whitten's medium.

as having formed a male pronucleus. The number of cells in blastocysts was determined by counting the number of orcein-stained nuclei.

\section{Assessment of developmental ability of embryos}

At $48 \mathrm{~h}$ after insemination, cleavage of oocytes was evaluated under a stereomicroscope and blastocyst formation was examined $144 \mathrm{~h}$ (day 6) and $168 \mathrm{~h}$ (day 7) after insemination.

\section{Statistical analysis}

Seven replicate trials for examination of oocyte nuclear maturation, fertilization and development were conducted. All percentage data were subjected to arc sine transformation before statistical analysis. Comparisons among maturation media were analysed by ANOVA. Three replicate trials for glutathione content and five replicate trials for cortical granules were conducted. The data were expressed as mean $\pm \mathrm{SD}$ and analysed by Student's t test.

\section{Results}

Effect of maturation media on nuclear maturation, sperm

penetration and male pronuclear formation

When oocytes were cultured in NCSU23, TCM-199 and mWM for $44 \mathrm{~h}$, a large proportion of oocytes (87-93\%) reached metaphase II and no differences $(P>0.05)$ were observed among the maturation media (Table 2). After being inseminated in mTBM, $71-76 \%$ of oocytes were penetrated by spermatozoa and $83-92 \%$ of oocytes formed MPN. Polyspermic oocytes were observed in $30-31 \%$ of oocytes, and the number of spermatozoa in penetrated oocytes was 1.33-1.71. No significant differences $(P>0.05)$ were found in these parameters among the maturation media.

\section{Quantification of cortical granule distribution and exocytosis in oocytes}

After maturation, cortical granules in all oocytes examined were located just beneath the oolemma and formed a monolayer irrespective of the maturation medium used. When observed in the top surface, cortical granules were distributed evenly in the cortex with $42.9 \pm 12.5$ to $46.3 \pm 6.3$ cortical granules per $100 \mu \mathrm{m}^{2}$ of the cortex. No differences in cortical granule density were observed in the oocytes cultured in the three maturation media. At $6 \mathrm{~h}$ after IVF, neither nuclear status (Fig. 1a) nor cortical granule distribution (Fig. 1a, b) changed in the oocytes without sperm penetration. However, in oocytes penetrated by spermatozoa, most of the spermatozoa were still at the stage of swollen head (Fig. Ic), and $78-84 \%$ of the cortical granules were released from oocytes with residual numbers of $7.0 \pm 3.1$ to $9.8 \pm 5.7$ cortical granules per $100 \mu \mathrm{m}^{2}$ of cortex (Fig. 1d), which was not different among the media used. However, at $12 \mathrm{~h}$ after IVF, almost all of the sperm heads had been transformed to MPN (Fig. Ie, g) and cortical granule density was significantly $(P<0.01)$ lower than at $6 \mathrm{~h}$ after IVF in oocytes matured in NCSU23, and $97 \%$ of cortical granules were released from the ooplasm (Fig. If, h). In contrast, the cortical granule density was similar at $6 \mathrm{~h}$ and $12 \mathrm{~h}$ after IVF for

Fig. 1. Confocal micrographs of cortical granules in pig oocytes matured in NCSU23 for $44 \mathrm{~h}$, and then inseminated in modified Tris buffer medium. Oocytes were examined $(a-d) 6 h$ and $(e-h) 12 \mathrm{~h}$ after insemination. Green and red images show cortical granules and DNA, respectively. (a, b) An oocyte that was not penetrated by spermatozoa at $6 \mathrm{~h}$ after insemination, still at the stage of metaphase II (M, metaphase; $\mathrm{pb}$, polar body). No cortical granule exocytosis was observed. $(c, d)$ An oocyte that was penetrated at $6 \mathrm{~h}$ after IVF by one spermatozoon (sp). The oocyte has been activated to form (c) a female pronucleus $(\mathrm{F})$, and (d) some cortical granules are still intact in the cortex. (e, $\mathrm{f}$ ) A penetrated oocyte at $12 \mathrm{~h}$ after IVF in which both male and female pronuclei have formed (e) and in which very few residual cortical granules were present in the cortex $(\hat{f}) .(\mathrm{g}, \mathrm{h})$ A polyspermic oocyte, observed $12 \mathrm{~h}$ after IVF, displaying three male pronuclei and one female pronucleus $(\mathrm{g})$, and very few cortical granules in the cortex (h). Scale bar represents $20 \mu \mathrm{m}$. 

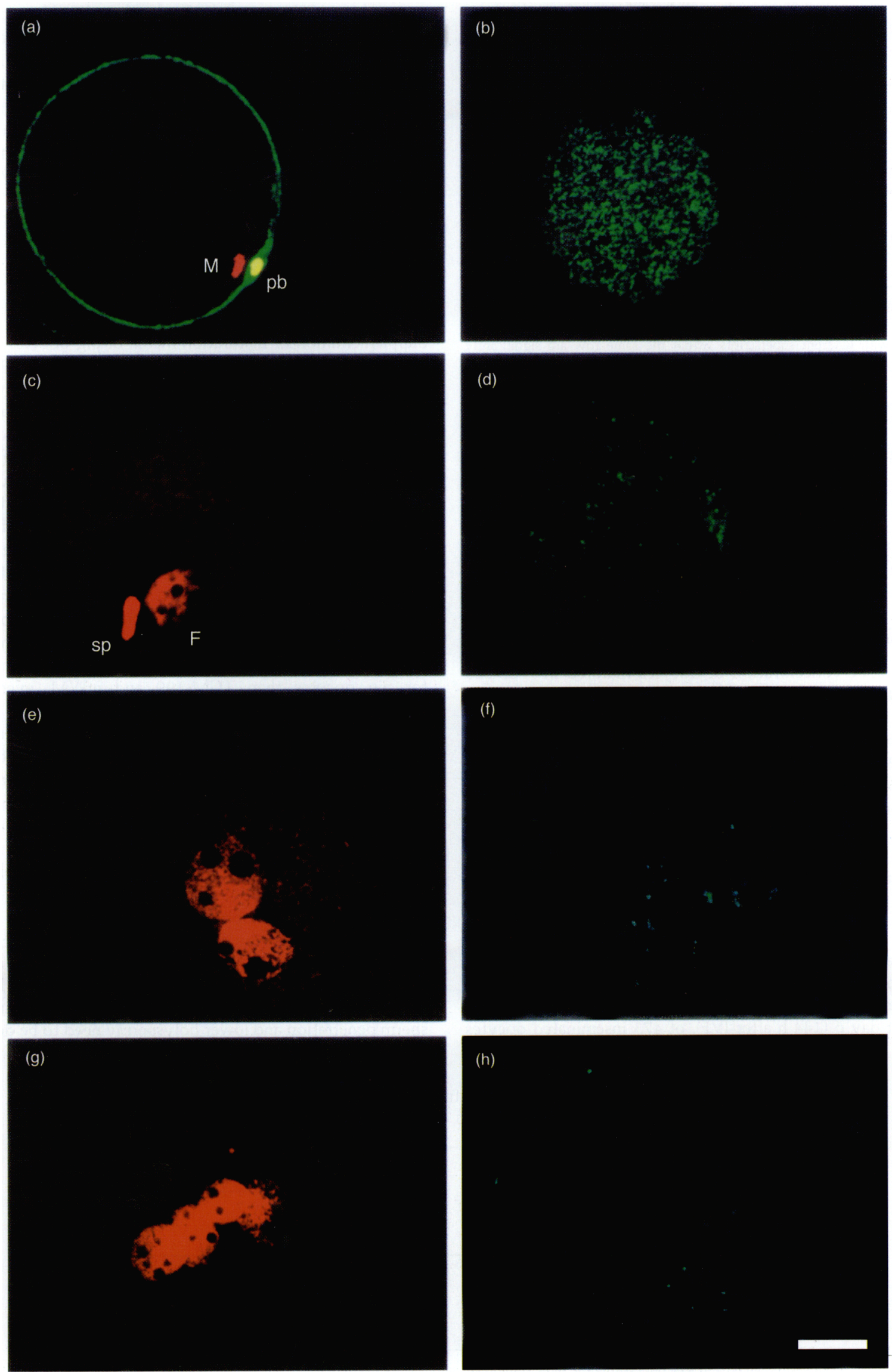
Table 3. Changes in cortical granule density of pig oocytes matured in different medium before and after in vitro fertilization (IVF)

\begin{tabular}{|c|c|c|c|}
\hline \multirow[b]{2}{*}{ Medium } & \multicolumn{3}{|c|}{$\begin{array}{c}\text { Mean } \pm \text { SD number of cortical granules } \\
\text { per } 100 \mu \mathrm{m}^{2} \text { of cortex }(n)\end{array}$} \\
\hline & Before IVF & $6 \mathrm{~h}$ after IVF & $12 \mathrm{~h}$ after IVF \\
\hline NCSU23 & $45.3 \pm 10.3^{A}(42)$ & $9.8 \pm 5.6^{\mathrm{B}}(32)$ & $1.5 \pm 1.3^{\mathrm{aC}}$ \\
\hline TCM-199 & $42.9 \pm 11.0^{\mathrm{A}}(46)$ & $7.0 \pm 3.3^{B}(24)$ & $6.1 \pm 4.8^{\mathrm{abB}}(30)$ \\
\hline $\mathrm{mWM}$ & $46.2 \pm 6.5^{\mathrm{A}}(44)$ & $9.1 \pm 5.7^{\mathrm{B}}(36)$ & $8.1 \pm 4.0^{\mathrm{bB}}$ \\
\hline
\end{tabular}

${ }^{\mathrm{ab}}$ Values with different superscripts within the same column are significantly different, $P<0.001$.

${ }^{A B C}$ Values with different superscripts within the same row are significantly different, $p<0.01$.

oocytes matured in TCM-199 and mWM (Table 3). The cortical granule density was similar for monospermic $(7.8 \pm 3.0$ to $10.0 \pm 6.4$ per $100 \mu \mathrm{m}^{2}$ at $6 \mathrm{~h}$, and $1.8 \pm 1.4$ to $8.7 \pm 4.3$ per $100 \mu \mathrm{m}^{2}$ at $\left.12 \mathrm{~h}\right)$ and polyspermic $(5.5 \pm 3.6$ to $9.3 \pm 3.5$ per $100 \mu \mathrm{m}^{2}$ at $6 \mathrm{~h}$, and $1.0 \pm 1.0$ to $6.9 \pm 2.9$ per $100 \mu \mathrm{m}^{2}$ at $12 \mathrm{~h}$ ) oocytes, although the latter tended to be lower at both $6 \mathrm{~h}$ and $12 \mathrm{~h}$ in all three maturation media.

\section{Intracellular glutathione content}

Glutathione concentration of oocytes matured in NCSU23 (5.8 $\pm 0.4 \mathrm{pmol}$ per oocyte, from 71 oocytes) was significantly higher $(P<0.05)$ than those matured in TCM-199 (3.6 \pm 0.6 pmol per oocyte, from 82 oocytes) or mWM $(2.3 \pm 0.8$ pmol per oocyte, from 63 oocytes). Oocytes matured in TCM-199 showed a higher $(P<0.05)$ concentration of glutathione compared with those cultured in mWM.

Effect of maturation media on developmental ability of oocytes after in vitro fertilization

At $48 \mathrm{~h}$ after IVF, $61-70 \%$ of the oocytes inseminated had cleaved and no differences were observed among the three maturation media, although NCSU23 showed a trend towards a higher rate of cleavage (70\%) than TCM-199 (61\%) or mWM $(61 \%)$. At day 6 (144 h after IVF), of 473 inseminated oocytes matured in NCSU23, 128 (27\%) developed to blastocysts, and at day 7 , this had increased to $30 \%$ (Table 4 ). These rates were significantly $(P<0.01)$ higher than those observed in TCM$199(15-19 \%)$ or in mWM (4-6\%). Oocytes matured in NCSU23 that developed into blastocysts had significantly $(P<0.05)$ more nuclei than oocytes matured in $\mathrm{mWM}$. Although a greater $(P<0.01)$ percentage of oocytes matured in TCM-199 developed into blastocysts than in $\mathrm{mWM}$, the number of nuclei per blastocyst did not differ (Table 4).

\section{Discussion}

Supplementation of maturation media of pig oocytes with pFF (Naito et al., 1988), cysteine (Yoshida et al., 1993a), and adjustment of hormonal conditions (Funahashi and Day, 1993b) during oocyte maturation enhances cytoplasmic maturation as measured by MPN formation after IVF. In this study, these conditions were combined and large proportions of oocytes formed MPN irrespective of the maturation medium used. However, when these oocytes were cultured further, the oocyte maturation medium used significantly affected the rate of development to blastocysts. More oocytes developed to blastocysts when matured in NCSU23 compared with TCM199 or mWM. A positive effect was observed for intracellular concentration of glutathione and the ability of oocytes to release cortical granules on blastocyst development. These results indicate that NCSU23 is a superior maturation medium for pig oocytes than TCM-199 and MWM, even in the presence of cysteine and $\mathrm{pFF}$.

Funahashi et al. (1996) reported that organic osmolyte components of NCSU23 were beneficial to cytoplasmic maturation of pig oocytes. When an organic osmolyte, such as sorbitol, is added to mWM during oocyte maturation, it increases blastocyst development, but the rate is still low $(<10 \%)$. Cytoplasmic maturation in that study was not fully developed. In the present study, when NCSU23, supplemented with cysteine and pFF, was used as the maturation medium, $30 \%$ of oocytes developed to blastocysts by day 7 . This was almost the same as the proportion of monospermic oocytes forming both male and female pronuclei. Therefore, it appeared that most of the normal zygotes that resulted from NCSU23 developed to blastocysts. Conditions that result in higher sperm penetration and lower polyspermy need to be developed

Table 4. Developmental ability of pig oocytes matured in different media, inseminated in modified Tris buffer medium (mTBM) and cultured in NCSU23

\begin{tabular}{lccccc}
\hline Medium & $\begin{array}{c}\text { Number of } \\
\text { oocytes } \\
\text { inseminated }\end{array}$ & $\begin{array}{c}\text { Number of } \\
\text { cleaved oocytes } \\
(\%)\end{array}$ & $\begin{array}{c}\text { Day } 6 \\
(\%)\end{array}$ & $\begin{array}{c}\text { Dayber of blastocysts } \\
(\%)\end{array}$ & $\begin{array}{c}\text { Mean number of } \\
\text { nuclei in day } 7 \\
\text { blastocysts }\end{array}$ \\
\hline NCSU23 & 473 & $332(70)$ & $128(27)^{\mathrm{a}}$ & $142(30)^{\mathrm{a}}$ & $36.8 \pm 17.0^{\mathrm{a}}$ \\
TCM-199 & 509 & $308(61)$ & $76(15)^{\mathrm{b}}$ & $97(19)^{\mathrm{b}}$ & $30.7 \pm 13.3^{\mathrm{ab}}$ \\
mWM & 529 & $321(61)$ & $21(4)^{\mathrm{c}}$ & $32(6)^{\mathrm{c}}$ & $29.4 \pm 12.0^{\mathrm{b}}$ \\
\hline
\end{tabular}

${ }^{\mathrm{ab}}$ Values with different superscripts within the same column are significantly different, $P<0.05$. mWM, modified Whitten's medium. 
to increase further the proportion of oocytes developing to blastocysts. In addition, although a high rate of blastocyst development was obtained in this study, the number of cells in the blastocysts was lower than in blastocysts developed in the oviduct after transfer (Funahashi et al., 1994a). Modifications in in vitro culture conditions are still necessary to increase the quality of embryos. A medium, BECM-3, that supports both the rate of blastocyst formation and a large number of cells in blastocysts has been developed for the culture of pig embryos produced in vivo (Dobrinsky et al., 1996). Whether this medium can also support development of IVM/IVF embryos needs to be examined further.

From this experiment, improved MPN formation and development of embryos may be the result of supplementation of cysteine in maturation. Supplementation of cysteine is important for glutathione synthesis (Yoshida et al., 1993a) and glutathione is necessary for sperm chromatin decondensation and, hence, for the formation of MPN in mouse (Calvin et al., 1986), hamster (Perreault et al., 1988) and pig (Yoshida et al., 1993a) oocytes. In the present study, when cysteine was added to three maturation media, high rates of MPN formation resulted and most $(83-92 \%)$ oocytes formed MPN. However, the ability of oocytes to develop to blastocysts was significantly different among media. Glutathione concentration is significantly higher in oocytes matured in NCSU23 than in TCM-199 or mWM. On the basis of the differences observed in the three media, it seems possible that the synthesis of glutathione by cumulusoocytes through cysteine is affected by other components in the medium. Components in the medium, such as taurine or hypotaurine in NCSU23, may also improve the synthesis of glutathione during oocyte maturation. Although the effectiveness of glutathione in enhancing embryo development has also been reported for bovine embryo development (Takahashi et al., 1993; Lim et al., 1996), the mechanism is not clear. Glutathione is an major intracellular free thiol that regulates cell proliferation, amino acid transport, synthesis of protein and DNA, and reduction of disulfides and other chemicals (Kosowa and Kosowa, 1978; Meister and Anderson, 1983), and all of these effects may be involved in embryo development.

Cortical granules are important organelles that play a central role in the zona block to polyspermic penetration during fertilization (Yanagimachi, 1994). Polyspermy is unusually high when pig oocytes are matured and inseminated in vitro (Niwa, 1993; Nagai, 1996). Delayed cortical granule exocytosis may be the main reason for polyspermy under in vitro conditions (Sathananthan and Trounson, 1982; Cran and Cheng, 1986). However, in the present study, $6 \mathrm{~h}$ after IVF (1-3 h after sperm penetration) approximately $80 \%$ of the cortical granules had been released from oocytes and no difference was found between monospermic and polyspermic oocytes. This finding suggests that pig oocytes cultured under the present conditions possess the ability to release cortical granules. The fertilization medium (mTBM) used in this study supported both sperm capacitation and oocyte cortical reaction. Polyspermy may be due to simultaneous sperm penetration (Hunter, 1991) or nonfunction of cortical granule exudate (Cran and Cheng, 1986). Conditions that support not only cortical granule exocytosis but also the activation of cortical granule exudate during IVF, such as increase of the availability of calcium (Cran and Cheng, 1986), should be examined further.
However, in oocytes $12 \mathrm{~h}$ after IVF, $97 \%$ of cortical granules had been released from oocytes matured in NCSU23, but there was no obvious decrease from $6 \mathrm{~h}$ in oocytes cultured in TCM199 or mWM. It has been suggested that cortical granules released at sperm penetration are critical for blocking polyspermy, and that the subsequent exocytosis is necessary to form a micro-environment around the oocyte, such as a complete cortical granule envelope (Dandekar and Talbot, 1992), which is beneficial for subsequent embryo development (Hoodbhoy and Talbot, 1994).

In conclusion, the present study indicates that cytoplasmic maturation of pig oocytes was significantly affected by maturation medium even in the presence of cysteine and pFF. When pig oocytes were cultured in BSA-free NCSU23 supplemented with pFF and cysteine, and then inseminated in mTBM by cryopreserved ejaculated spermatozoa, a large proportion of the fertilized oocytes developed to blastocysts in culture. The ability of oocytes to synthesize glutathione and release cortical granules are two additional important criteria for assessment of cytoplasmic maturation in pig oocytes.

The authors thank T. Phillips, N. Elisabeth and C. Okamura of the Molecular Cytology Core Facility at the University of Missouri-Columbia for use of confocal microscope and preparing photomicrographs, and B. Nichols for secretarial assistance in preparation of the manuscript. W. H. Wang is the recipient of a Food for the 21st Century Postdoctoral Fellowship at the University of Missouri-Columbia. This manuscript is a contribution from the Missouri Agricultural Experiment Station, Journal Series Number 12609 .

\section{References}

Abeydeera LR and Day BN Fertilization and subsequent development in vitro of pig oocytes inseminated in a modified Tris-buffered medium with frozenthawed ejaculated spermatozoa Biology of Reproduction (in press)

Anderson ME (1985) Determination of glutathione and glutathione disulfide in biological samples. In Glutamate, Glutamine, Glutathione and Related Compounds pp 548-555 Ed. A Meister. Academic Press, New York

Beckmann LS and Day BN (1993) Effects of media $\mathrm{NaCl}$ concentration and osmolarity on the culture of early-stage pig embryos and the viability of embryos cultured in a selected superior medium Theriogenology 39611-622

Berger T and Horton MB (1988) Evaluation of assay conditions for the zona-free hamster ova bioassay of boar sperm fertility Gamete Research 19 $101-111$

Calvin HI, Grosshans K and Blake EJ (1986) Estimation and manipulation of glutathione levels in prepuberal mouse ovaries and ova: relevance to sperm nucleus transformation in the fertilized egg Gamete Research 14 265-275

Cran DG and Cheng WTK (1986) The cortical reaction in pig oocytes during in vivo and in vitro fertilization Gamete Research 13 241-251

Dandekar P and Talbot P (1992) Perivitelline space of mammalian oocytes: extracellular matrix of unfertilized oocytes and formation of a cortical granule envelope following fertilization Molecular Reproduction and Development 31 135-143

Dobrinsky JR, Johnson LA and Rath D (1996) Development of a culture medium (BECM3) for pig embryos: effects of bovine serum albumin and fetal bovine serum on embryo development Biology of Reproduction 55 1069-1074

Funahashi H and Day BN (1993a) Effects of different serum supplements in maturation medium on meiotic and cytoplasmic maturation of pig oocytes Theriogenology 39 965-973

Funahashi H and Day BN (1993b) Effects of the duration of exposure to supplemental hormones on cytoplasmic maturation of pig oocytes in vitro. Journal of Reproduction and Fertility 98 179-185

Funahashi H, Stumpf TT, Terlouw SL, Cantley T, Rieke A and Day BN (1994a) Developmental ability of pig oocytes matured and fertilized in vitro. Theriogenology 41 1425-I433 
Funahashi H, Cantley T, Stumpf TT, Terlouw SL, Rieke A and Day BN (1994b) In vitro development of in vitro-matured pig oocytes following chemical activation or in vitro fertilization Biology of Reproduction 50 1072-1077

Funahashi H, Cantley T, Stumpf TT, Terlouw SL and Day BN (1994c) Use of low-salt culture medium for in vitro maturation of pig oocytes is associated with elevated oocytes glutathione level and enhanced pronuclear formation after in vitro fertilization Biology of Reproduction $\mathbf{5 1} 633-639$

Funahashi H, Kim NH, Stumpf TT, Cantley T and Day BN (1996) Presence of organic osmolytes in maturation medium enhances cytoplasmic maturation of pig oocytes Biology of Reproduction 54 1412-1419

Hoodbhoy T and Talbot P (1994) Mammalian cortical granules: contents, fate, and function Molecular Reproduction and Development 39 439-448

Hunter RHF (1991) Oviduct function in pigs, with particular reference to the pathological condition of polyspermy Molecular Reproduction and Development 29 385-391

Kosowa NS and Kosowa EM (1978) The glutathione status of cells International Review of Cytology $\mathbf{5 4}$ 109-160

Lim JM, Lious SS and Hansel W (1996) Intracytoplasmic glutathione concentration and the beta-mercaptoethanol in preimplantation development of bovine embryos Theriogenology 46 429-439

Mattioli M, Bacci ML, Galeati G and Seren E (1989) Developmental competence of pig oocytes matured and fertilized in vitro. Theriogenology 31 1201-1207

Meister A and Anderson ME (1983) Glutathione Annual Review of Biochemistry $52711-760$

Nagai $\mathrm{T}$ (1996) in vitro maturation and fertilization of pig oocytes Animal Reproduction Science 42 153-163

Nagashima H, Nagai T and Yamakawa $\mathrm{H}$ (1993) In vitro development of in vivo and in vitro fertilized pig zygotes Journal of Reproduction and Development 2 $163-168$

Naito K, Fukuda Y and Toyoda Y (1988) Effect of pig follicular fluid on male pronucleus formation in pig oocytes matured in vitro. Gamete Research 21 289-295

Niwa K (1993) Effectiveness of in vitro maturation and in vitro fertilization techniques in pigs Journal of Reproduction and Fertility Supplement 48 49-59
Perreault SD, Barbee RR and Slott VL (1988) Importance of glutathione in the acquisition and maintenance of sperm nuclear decondensing activity in maturing hamster oocytes Developmental Biology 125 181-186

Petters RM and Wells KD (1993) Culture of pig embryos Journal of Reproduction and Fertility Supplement 48 61-73

Rath D, Niemann H and Torres CRL (1996) in vitro development to blastocysts of early pig embryos produced in vivo and in vitro. Theriogenology $\mathbf{4 3}$ 913-921

Sathananthan AH and Trounson AO (1982) Ultrastructure of cortical granule release and zona interaction in monospermic and polyspermic human ova fertilized in vitro. Gamete Research 6 225-234

Takahashi M, Nagai T, Hamano S, Kuwayama M, Okamura N and Okano A (1993) Effect of thiol compounds on in vitro deveiopment and intracellular glutathione content of bovine embryos Biology of Reproduction 49 228-232

Wang WH, Niwa K and Okuda K (1991) in vitro penetration of pig oocytes matured in culture by frozen-thawed ejaculated spermatozoa Journal of Reproduction and Fertility 93 491-496

Whitten WK and Biggers JD (1968) Complete development in vitro of the pre-implantation stages of the mouse in a simple chemically defined medium Journal of Reproduction and Fertility 17 399-401

Yanagimachi R (1994) Mammalian fertilization. In The Physiology of Reproduction pp 261-268 Eds E Knobil and JD Neill. Raven Press, New York

Yoshida M, Ishigaki Y and Kawagishi H (1990) Blastocyst formation by pig embryos resulting from in vitro fertilization of oocytes matured in vitro. journal of Reproduction and Fertility 88 1-8

Yoshida M, Ishigaki K, Nagai T, Chikyu M and Pursel VG (1993a) Glutathione concentration during maturation and after fertilization in pig oocyte: relevance to the ability of oocytes to form male pronucleus Biology of Reproduction 49 89-94

Yoshida M, Cran DG and Pursel VG (1993b) Confocal and fluorescence microscopic study using lectins of the distribution of cortical granules during the maturation and fertilization of pig oocytes Molecular Reproduction and Development $36462-468$ 